\title{
MEDIDAS PROTETIVAS DE URGÊNCIA E AS EXPECTATIVAS DE SEGURANÇA PARA MULHERES EM SITUAÇÃO DE VIOLÊNCIA DOMÉSTICA
}

\author{
MEDIDAS PROTECTIVAS DE URGENCIA Y EXPECTATIVAS DE \\ SEGURIDAD PARA MUJERES EN SITUACIÓN DE VIOLENCIA \\ DOMÉSTICA
}

\author{
Rita de Cássia Barbosa de Sousa \\ Universidade Estadual do Sudoeste da Bahia/UESB
}

Tânia Rocha Andrade Cunha Universidade Estadual do Sudoeste da Bahia/UESB

\section{Resumo}

O presente trabalho trata da importância das Medidas Protetivas de Urgência previstas na Lei Maria da Penha para a segurança de mulheres que denunciam a violência doméstica. Realizamos uma coleta de dados na Delegacia Especial de Atendimento à Mulher/DEAM, de Vitória da Conquista-Bahia, averiguando registros de ocorrências desse tipo de crime, dos respectivos inquéritos policiais e solicitações de Medidas Protetivas. Também foi realizada análise documental no intuito de identificarmos os casos de denúncias que foram acompanhados de solicitação dessa medida cautelar e posterior desistência da denunciante, restando evidente que muitas mulheres têm denunciado as violências e solicitado medidas protetivas, ratificando o desejo por uma vida sem violência. No entanto, ante o Mandado de Afastamento expedido pela Justiça e o respectivo cumprimento pelo agressor, sucederam várias situações de Retratação da Representação Criminal, seja por uma suposta sensação de segurança ou mesmo pela impressão de que o problema se encontrava resolvido. Assim, o fenômeno da desistência pleiteada nessas situações é uma realidade que suscita reflexões ligadas não somente às várias formas de enfrentamento envidadas pelas mulheres, mas também à necessidade de novos olhares para a dimensão da violência doméstica. 
Palavras-chave: Mulheres. Violência Doméstica. Lei Maria da Penha. Medidas Protetivas de Urgência.

\section{Resumen}

El presente trabajo trata da importancia de las Medidas Protetivas de Urgência previstas en la Ley Maria da Penha para la seguridad de mujeres que denuncian la violencia doméstica. Se realizó una recolección de datos en la Delegacia Especial de Atendimento à Mulher/DEAM, de Vitória da Conquista-Bahía, averiguando registros de ocurrencias de ese tipo de crimen, de las respectivas encuestas policiales y solicitudes de Medidas Protectivas. También se realizó un análisis documental con el fin de identificar los casos de denuncias que fueron acompañados de la solicitud de esa medida cautelar y posterior desistimiento de la denunciante, quedando evidente que muchas mujeres han denunciado las violencias y solicitado medidas protectivas, ratificando el deseo por una vida sin violencia. Sin embargo, ante el Mandado de Afastamento (Mandamiento de Separación) expedido por la Justicia y su cumplimiento por el agresor, sucedieron varias situaciones de Retratación de la Representación Criminal, sea por una supuesta sensación de seguridad o incluso por la impresión de que el problema se encontraba resuelto. Así, el fenómeno de la desistencia pleiteada en esas situaciones es una realidad que suscita reflexiones ligadas no sólo a las diversas formas de enfrentamiento envidadas por las mujeres, sino también a la necesidad de nuevas miradas para la dimensión de la violencia doméstica.

Palabras clave: Mujeres. Violencia doméstica. Ley Maria da Penha. Medidas Protectivas de Urgencia.

\section{Introdução}

A violência doméstica contra as mulheres está presente na estrutura das sociedades e constitui a manifestação de uma cultura sexista que representa os resquícios do patriarcado, que engendra iniquidades à figura do feminino. Seu enfrentamento implica promoção de políticas públicas que promovam reconhecimento e compreensão desse fenômeno social. 

PARA MULHERES EM SITUAÇÃO DE VIOLÊNCIA DOMÉSTICA

A luta das mulheres por uma vida sem discriminação e violência é histórica e podemos apontar a adoção, em 09 de junho de 1994, da Convenção Interamericana para Prevenir, Punir e Erradicar a Violência Contra a Mulher - Convenção de Belém do Pará, por parte da Assembléia Geral da Organização dos Estados Americanos - OEA, como um dos marcos de combate a esse tipo de violência, em que se estabeleceu que a eliminação da violência contra a mulher é condição indispensável para seu desenvolvimento individual e social como sujeito de direitos, bem como para sua plena e igualitária participação em todas as esferas da vida. A Convenção de Belém do Pará é aprovada pelo Estado brasileiro em 1995, mediante o Decreto Legislativo $\mathrm{n}^{\text {o }}$ 107, de $1^{\text {o }}$ de setembro de 1995 (Agende, 2004).

A partir da Convenção de Belém do Pará, surgiram importantes mecanismos para a proteção internacional dos direitos humanos das mulheres, a exemplo das petições à Comissão Interamericana de Direitos Humanos, para o caso de descumprimento dos compromissos assumidos pelos Estados-partes perante o Sistema Interamericano de Direitos Humanos, estabelecendo os critérios para fazê-lo. Além de trazer em seu Art. $1^{\circ}$ a definição de violência contra a mulher como "qualquer ato ou conduta baseada no gênero, que cause morte, dano ou sofrimento físico, sexual ou psicológico à mulher, tanto na esfera pública como na esfera privada", preceitua que toda mulher tem direito ao reconhecimento, desfrute, exercício e proteção de todos os direitos humanos consagrados e, dentre outros ali especificados, destacou em seu Art. 4", item c, o "direito à liberdade e à segurança pessoais" (OEA, 1994).

Sentir-se segura se constitui um direito humano das mulheres e esse destaque na lei não foi mero acaso, tendo em vista que, na mesma vertente mundial, o Brasil também se insere no contexto de um país de alta incidência de violência doméstica. A Pesquisa publicada pela Fundação Perseu Abramo (2010, p. 57) intitulada "Mulheres Brasileiras e Gênero nos Espaços Público e Privado", o Capítulo V é dedicado à problemática desse tipo de violência, em que consta que as entrevistadas, ao serem indagadas sobre o que mudariam para que a vida de todas as mulheres melhorasse, elas responderam sobre suas expectativas, dentre as que foram mencionadas: "Proteger a mulher vítima da violência/ mais segurança para as mulheres que apanham/sofrem com os maridos". A garantia da segurança das mulheres que denunciam é fundamental para o encorajamento de outras que se encontram em situação semelhante, por esse motivo o combate à violência doméstica contra as mulheres se constitui um dos principais motes da luta de movimentos feministas e de mulheres em nosso país. 
De acordo com Cavalcanti, (2012, p. 55), a violência doméstica ocorre entre membros de uma mesma família ou mesmo que partilham do mesmo espaço de habitação, o que torna a problemática dessa violência algo especialmente complexo, “com facetas que entram na intimidade das famílias e das pessoas (agravado por não ter, regra geral, testemunhas e ser exercida em espaços privados)", o que aumenta ainda mais seu potencial ofensivo, porquanto "não se pode tratar da mesma maneira um delito praticado por um estranho e o mesmo delito praticado por alguém de estreita convivência, como é o caso de maridos, companheiros, namorados, atuais ou anteriores".

Nesse sentido, a promulgação da Lei 11.340/06, Lei Maria da Penha, é resultado desse enfrentamento, pois se trata de uma lei específica para atender a complexidade da violência doméstica contra as mulheres. Além de possuir mecanismos de assistência às vítimas e de prever uma punição mais rigorosa para os autores desse tipo de crime, traz de modo detalhado todos os procedimentos cautelares que devem ser cumpridos para que as mulheres que denunciam a violência doméstica se sintam protegidas ante as reações de muitos daqueles que não se conformam com a atitude de enfrentamento dessas vítimas.

Desse modo, o artigo discute a importância das Medidas Protetivas de Urgência previstas na Lei Maria da Penha para mulheres que enfrentam a violência doméstica e denunciam seus agressores. Procuramos também identificar como tem se configurado o uso dessa medida cautelar por parte dessas mulheres, inclusive refletir sobre as situações em que muitas delas abrem mão desse direito previsto em lei.

\section{Metodologia}

No intuito de identificarmos como vem ocorrendoa utilização da solicitação de Medida Protetiva de Urgência, enquanto mecanismo de enfrentamento à violência doméstica por parte daquelas que denunciam seus agressores, procuramos verificar os registros de boletins de ocorrência que denunciam esse tipo de crime, nos termos da Lei Maria da Penha, a respectiva solicitação de Medidas Protetivas de Urgência-MPU, e a posterior desistência do procedimento, para termos uma visão mais ampla desse fenômeno que é vivenciado por muitas mulheres. 


\section{MEDIDAS PROTETIVAS DE URGÊNCIA E AS EXPECTATIVAS DE SEGURANÇA PARA MULHERES EM SITUAÇÃO DE VIOLÊNCIA DOMÉSTICA}

Nesse sentido, realizamos uma coleta de dados na Delegacia Especial de Atendimento à Mulher - DEAM - de Vitória da Conquista, observando os quantitativos dos anos de 2009 a 2017 que envolveram denúncias de crimes de violência doméstica comrequerimento de Medida Protetiva de Urgência.

Com o objetivo de identificarmos como se procederam os retornos das mulheres para pleitearem a desistência e as alegações por elas suscitadas, utilizamos no presente estudo algumas transcrições provenientes de análises documentais que foram realizadas durante nossa pesquisa de mestrado ${ }^{\mathrm{i}}$, que tratou da violência doméstica no âmbito da conjugalidade e da Retratação da Representação Criminal ${ }^{\mathrm{ii}}$ por parte de muitas daquelas que denunciam seus agressores, pois verificamos que em muitos desses procedimentos de Retratação, as vítimas também haviam solicitado Medidas Protetivas.

As denúncias realizadas pelas mulheres que vão às DEAMs se tornam boletins de ocorrência que são inseridos nos inquéritos policiais. As narrativas constantes no histórico dos boletins de ocorrência contêm de modo sucinto a notícia do crime informado pela denunciante e os demais itens exigidos pela instituição policial. Os detalhes são narrados posteriormente em "Termos de Declarações". As análises documentais foram elaboradas a partir das declarações dessas mulheres.

De acordo com Saffioti (1995, p.72), essas mulheres "Dispõem das suas histórias e daquelas vividas ou relatadas por pessoas com as quais privaram e que deixaram marcas em sua memória". Desse modo, acreditamos que as reflexões realizadas a partir das análises desses documentos nos auxiliam a compreender a problemática da violência contra as mulheres e as múltiplas formas de enfrentamento por elas empreendidas.

\section{Resultados e Discussões}

3.1 A Lei Maria da Penha e as Medidas Protetivas de Urgência

A Lei Maria da Penha, Lei 11.340 de 07 de agosto de 2006, é um avanço da legislação, dentro do ordenamento jurídico do Brasil, não somente por tratar assuntos ligados a vários ramos do Direito, mas por sua busca em coibir a violência contumaz praticada por homens contra mulheres com as quais mantiveram/mantêm algum vínculo afetivo, tendo como objetivo garantir às mulheres o direito a uma vida sem violência, cujos fundamentos estão em consonância com as Convenções Internacionais de que o Brasil é signatário, quais 
sejam: Convenção sobre a Eliminação de Todas as Formas de Violência Contra as Mulheres e a Convenção Interamericana para Prevenir, Punir e Erradicar a Violência Contra a Mulher.

As mulheres em situação de violência doméstica necessitam de proteção integral aos seus direitos e, por esse motivo, a Lei Maria da Penha possui ampla abrangência: Art. $8^{\text {o: }}$ "A política pública que visa coibir a violência doméstica e familiar contra a mulher far-se-á por meio de um conjunto articulado de ações da União, dos Estados, do Distrito Federal e dos Municípios e de ações não governamentais [...]. Esse mesmo Artigo também trata da assistência à mulher em situação de violência doméstica e familiar e especifica as medidas integradas de prevenção (BRASIL, 2006, Lei 11.340/06).

A Lei Maria da Penha trata das Medidas Protetivas de Urgência em seu Capítulo II, Artigos de 18-23, dispondo sobre o modo como se deve proceder os expedientes de solicitação de MPU, no entanto, é possível encontrarmos outras medidas de proteção nos demais artigos do texto legal. Essas providências visam evitar que ocorram outras violações de direitos, posteriores à denúncia, por isso estabelece obrigações específicas para o agressor, medidas que são aplicadas às vítimas, tanto de caráter pessoal, quanto patrimonial, bem como as que envolvem as demandas de relações de trabalho.

Para Cavalcanti (2012, p. 234), a importância das medidas protetivas contidas na Lei Maria da Penha se deve ao fato de elas possibilitarem à vítima a solução de problemas que demandam urgência, antes mesmo do início do processo criminal, e escreve:

Existem algumas medidas urgentes que necessitam ser realizadas imediatamente após a ocorrência do crime de Violência doméstica, tais como: o afastamento do réu no lar; a estipulação de alimentos provisionais à vítima e à prole; a possibilidade de a mulher retornar à casa para retirar seus pertences, entre outras, que agora podem ser deferidas de pronto pelo juiz competente para processar e julgar os delitos de VD.

Dias (2012, p. 147-148) destaca que existem debates sobre a doutrina sobre a natureza jurídica das medidas protetivas, e afirma que elas "não são instrumentos para assegurar processos", pois têm como finalidade proteger direitos fundamentais, impedindo a continuidade da violência e de situações que de algum modo a favoreçam, ou seja, não são requisitos preparatórios de qualquer ação judicial, visto que "não visam processos, mas pessoas". 


\section{MEDIDAS PROTETIVAS DE URGÊNCIA E AS EXPECTATIVAS DE SEGURANÇA PARA MULHERES EM SITUAÇÃO DE VIOLÊNCIA DOMÉSTICA}

De acordo com Souza (2009), as medidas protetivas de urgência são consideradas cautelares, pois têm como meta garantir de modo especial a integridade psicológica, física, moral e patrimonial da mulher vítima de violência doméstica e familiar, objetivando também assegurar que ela possa agir livremente ao optar por buscar a proteção do Estado contra seu agressor.

Assim, em se tratando de violência doméstica, as providências legais se constituem urgentes e indispensáveis, tanto para aquelas que ainda se encontravam coabitando com o agressor, quanto para as que já haviam rompido o relacionamento à ocasião das denúncias. Essasprovidências visam assegurar os direitos humanos das mulheres.

\subsection{Registros de inquéritos policiais e as solicitações de Medidas Protetivas}

As Delegacias Especializadas de Atendimento à Mulher - DEAMs, são órgãos ligados à Polícia Civil, que fazem parte da Secretaria da Segurança Pública do Estado. Nesses locais, a maior parte das vítimas de violência doméstica registram as denúncias de crimes de violência doméstica. Os registros de ocorrência desse tipo de violência, com base na Lei Maria da Penha, geram instauração de Inquérito Policialiii. Grande parte dessas investigações envolvem solicitação de Medida Protetiva de Urgência.

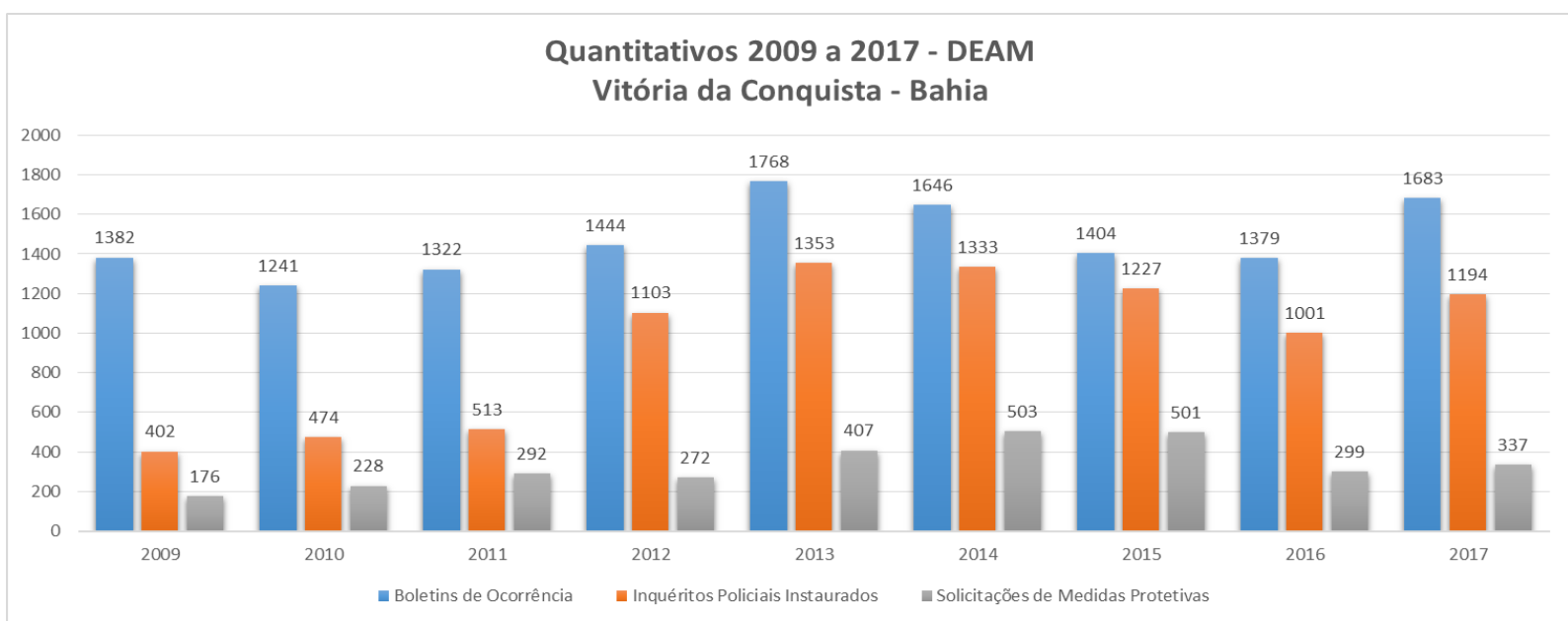

Gráfico 01- Quantitativos de Ocorrências, Inquéritos Policiais Instaurados e solicitações de Medidas Protetivas de Urgência dos anos de 2009 a 2017.

Fonte: DEAM de Vitória da Conquista-BA - Disposição em gráfico elaborada pela autora 
O gráfico 1 traz uma visão panorâmica do número de Boletins de Ocorrência registrados no decorrer dos anos de 2009 a 2017, seguidos dos quantitativos de registros de inquéritos policiais e de solicitações de Medida Protetiva de Urgênciaiv ${ }^{\text {iv }}$ Esses dados revelam que as implantações das DEAMs deram visibilidade à violência doméstica contra a mulher e que as vítimas têm recorrido às solicitações de Medida Protetiva de Urgência para garantir a proteção de seus direitos.

Observamos que no decorrer dos anos de 2012 a 2015 ocorreram aumentos nas porcentagens de solicitações de MPU em relação ao número de Inquéritos Policiais registrados, situação que só modificou no ano de 2016, quando houve uma diminuição considerável nas solicitações de MPU que atingiu a ordem de 40,3\% a menos que o ano de anterior, percentual que não se justifica, se comparado ao número de registros de Inquéritos Policiais, cujo decréscimo ocorreu em apenas 18,4\%. Indagamos na DEAM acerca desse decréscimo e fomos informados que pode ter ocorrido de as denunciantes não terem sido devidamente informadas no ato do Registro de Boletim de Ocorrência sobre o direito a Medidas Protetivas, e que tal diminuição foi percebida nessa Delegacia Especializada.

Quanto aos dados relativos ao ano de 2017 , eles demonstram que o número de solicitações de MPU permanecem com a mesma representatividade em razão do número de inquéritos policiais registrados, não havendo mudança significativa, permanecendo inferior a 30\%. Esses decréscimos nos anos de 2016 e 2017 fugiram ao padrão ascendente dos anos anteriores, quando tivemos percentuais de $24,7 \%$ em 2012, aumentando para 30,1\% em 2013, $37,7 \%$ em 2014, chegando a 40,8\% no ano de 2015. 


\section{MEDIDAS PROTETIVAS DE URGÊNCIA E AS EXPECTATIVAS DE SEGURANÇA PARA MULHERES EM SITUAÇÃO DE VIOLÊNCIA DOMÉSTICA}

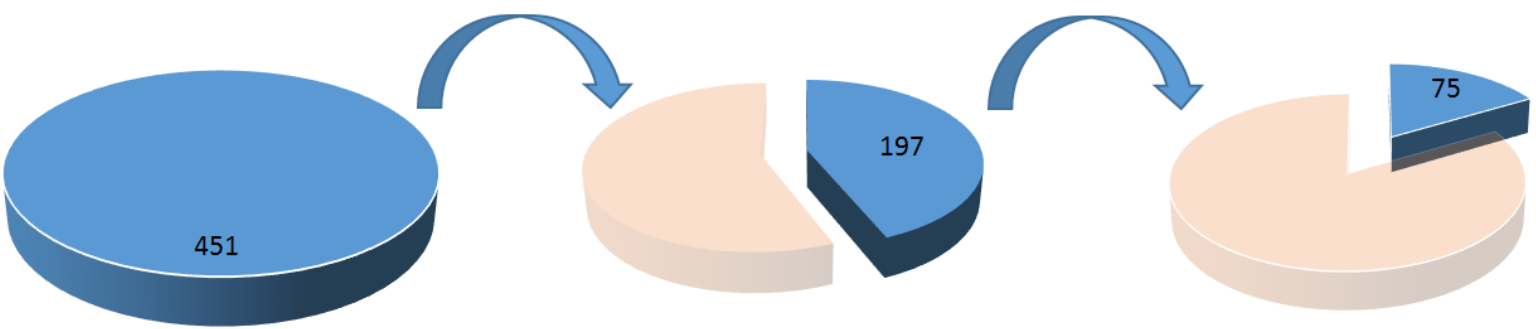

- Inquéritos que dependem de Representação Criminal

• Houve retratação da representação criminal

- Solicitaram Medida Protetiva

Gráfico 2 - Quantitativo de Inquéritos Policiais registrados em 2012 que dependiam de Representação Criminal

Fonte: DEAM de Vitória da Conquista - Disposição em gráfico elaborada pela autora

No ano de 2012, a DEAM registrou o total de 1.444 inquéritos policiais provenientes de violência doméstica por diversos tipos de crimes: Ameaça, Lesão Corporal, Homicídio Tentado, Calúnia, Difamação, Injúria, Estupro, respectivamente: Artigos 147, 129, §9º 121, c/c art. II, 138, 139, 140 e Art. 213, todos do Código Penal Brasileiro, nos termos da Lei 11.340/06, além de outros crimes. Desse total, 451 procedimentos dependiam de Representação Criminal da vítima para indiciamento do (s) agressor (es). NoGráfico $\mathrm{n}^{\circ}$ 2, vemos que desse quantitativo, 197 mulheres retornaram para pleitear a Retratação da Representação Criminal, o que representa aproximadamente 44\% ${ }^{v}$. Desses casos, 197 retratações foram pleiteadas pelas vítimas, sendo que, em 75 deles, a MPU já havia sido solicitada.

Assim, procuramos identificar nesses inquéritos com solicitação de MPU, acompanhados de Retratação, as alegações suscitadas pelas mulheres para manifestarem não ter interesse em dar continuidade aos procedimentos, identificando que algumas mulheres tomam as providências para a suspensão da Medida Protetiva, acreditando que tiveram seus dilemas resolvidos, conforme nos mostra a Transcrição 0183/2012:

[...] Que se arrependeu de se separar dele[...] Que em relação à Medida Protetiva que solicitou, quando o Oficial de Justiça esteve na casa da declarante, informou que já tinham se reconciliado, por isso não foi cumprida a medida.

No entanto, nem sempre a Retratação vem acompanhada de retomada ao relacionamento ou mesmo de desistência da Medida Protetiva. Na Transcrição seguinte, vemos que a mulher quer deixar a convivência com o agressor, solicita Medida Protetiva, mas não quer que ele fique preso, enaltecendo suas qualidades de "boa pessoa e trabalhador":

Que ele é boa pessoa e trabalhador, mas quando bebe, fica nervoso e alterado, motivo este que levou a declarante a não querer mais conviver com ele. Que não deseja Representar Criminalmente contra ele pelos fatos acima

\begin{tabular}{l|l} 
Revista RBBA & Revista Binacional Brasil Argentina
\end{tabular} 
narrados, entretanto solicita a autoridade policial que ele seja afastado do lar (Transcrição 423/2012).

A Transcrição se refere a uma ocorrência policial de violência doméstica apresentada no Plantão de Polícia ${ }^{\text {vi }}$. Nesse procedimento, o agressor foi conduzido e apresentado, bem como vítima e testemunhas, que em geral são policiais militares. Desse modo, declarando que não quer providências policiais, a não ser a Medida Protetiva. Desse modo, o agressor não foi autuado em flagrante, sendo liberado pela Autoridade Policial. A solicitação de MPU será encaminhada para a Justiça por meio do Plantão Central ou, posteriormente, pela DEAM. Tal situação é complexa para a vítima, pois, até que ocorra o Mandado de Afastamento, que é prerrogativa da Justiça, o agressor permanecerá com a vítima no mesmo local de convivência, o que não deveria ocorrer, pois muitos homens ficam ainda mais agressivos quando deixam a delegacia e retornam para suas casas. Essa tem sido uma situação de risco iminente enfrentada por muitas mulheres vítimas de violência doméstica, em especial, por não haver casas-abrigo na cidade de Vitória da Conquista.

Um aspecto importante da relação conjugal violenta é a questão da ambivalência vivida pelas mulheres que enfrentam conflitos que envolvem a repulsa da violência e a afeição que mantém pelo parceiro agressor. Sobre essa dificuldade, Cunha (2007, p. 192), afirma que:

A maioria das mulheres costuma falar de homens que são, ao mesmo tempo, "bons" e "maus", parecendo não perceber que os atos de violência perpetrados contra elas não são fatos isolados, mas que estão inseridos na dinâmica da relação que configura a vida do casal. O mesmo homem que desrespeita, humilha, ameaça e bate na sua companheira é também o que afaga, sustenta, protege, é bom profissional, bom pai e bom amante.

Muitas vítimas não levam adiante o procedimento policial contra o agressor porque, ante a decretação do Mandado de Afastamento expedido pela Justiça, alguns autores cumprem a ordem judicial e se afastam, o que acaba trazendo uma sensação de segurança para aquelas que efetuaram a denúncia, tendo em vista que estavam vivendo sob constante ameaça. Num procedimento de desistência, uma mulher relatou que não queria mais dar continuidade ao procedimento, pois "Ele cumpriu o que determina a Medida Protetiva de Urgência (Transcrição 01/ 2012).

Por outro lado, há mulheres que pedem Retratação, mas não abrem mão da solicitação de MPU, acreditando que este é o modo que conseguirão se separar do agressor. De fato, é considerável o número de mulheres que foram vítimas de violência doméstica apenas por 


\section{MEDIDAS PROTETIVAS DE URGÊNCIA E AS EXPECTATIVAS DE SEGURANÇA PARA MULHERES EM SITUAÇÃO DE VIOLÊNCIA DOMÉSTICA}

terem demonstrado interesse em se separar, algumas delas nem mantinham convivência à época dos fatos.

Não podemos deixar de lado uma realidade: há vítimas que se retratam da representação criminal e até mesmo da Medida Protetiva por terem sido forçadas a tal atitude. Saffioti (1997, p. 54) chama a atenção para a realidade da ameaça velada: "Muitas vezes, o marido, tomando conhecimento da apresentação de queixa à DDM por parte da mulher, ameaça-a de morte, caso não obedeça sustando o inquérito". Assim, as desistências envolvem situações que necessitam de atenção especial, visto que podem camuflar ameaças veladas e aumentarem ainda mais a vulnerabilidade de mulheres que estão enfrentando a violência doméstica.

\section{Considerações finais}

De um modo geral, as denúncias de violência doméstica ganharam a necessária visibilidade com a implantação das DEAMs e seu funcionamento foi alterado substancialmente com a promulgação da Lei Maria da Penha, que introduziu as medidas protetivas e urgência em favor das vítimas, possibilitando, dentre vários outros aspectos, o afastamento do agressor do lar e seu distanciamento obrigatório. Além disso, a decretação de prisão preventiva, nas situações em que houver riscos à integridade física da denunciante.

Enquanto mecanismo cautelar, as Medidas Protetivas são fundamentais para que as mulheres que denunciam se sintam seguras após o registro da ocorrência policial, tanto que a Lei Maria da Penha destacou o modo como o atendimento deve ser prestado nas delegacias especializadas, por isso as DEAMs devem velar pela aplicação dessa lei em todos os aspectos que envolvem o atendimento às vítimas, e tomada de providências inerentes aos requerimentos de Medidas Protetivas.

Em várias situações analisadas, vimos que um número considerável de mulheres que denunciam seus agressores e solicitam Medida Protetiva acabam se retratando da Representação Criminal, por acreditarem que o problema que as levou a registrar o boletim de ocorrência foi resolvido, principalmente quando a ameaça da qual foram vítimas tinha como motivação o interesse em romper o relacionamento ou mesmo de oficializar uma separação quando a convivência já nem existia.

No entanto, sabemos que a exemplo de outras leis existentes no Brasil que implicam medidas de segurança para quem denuncia algum tipo de violência, as Medidas Protetivas de 
Urgência muitas vezes têm se mostrado ineficazes para impedirem que mulheres sejam novamente agredidas ou até mesmo mortas pelos companheiros e/ou ex-companheiros, havendo mesmo uma necessidade de adequação dos órgãos de segurança pública para cumprirem as demandas abrangentes da Lei Maria da Penha.

Destacamos que a Medida de Afastamento expedida pelo Juiz de Direito e a respectiva obediência pelo agressor fizeram com que muitas mulheres se retratassem. Isso nos indica que há uma tendência das mulheres em não querer que seus agressores sejam punidos com o processo criminal e a prisão. No entanto, acreditamos que as mulheres que denunciam seus agressores pleiteiam retomar a autonomia sobre suas vidas.

As atitudes dessas mulheres frente às várias situações vivenciadas são resultado de combinações múltiplas de fatores que demonstram a complexidade do enfrentamento da violência doméstica e, nesse contexto, as denúncias e solicitações de Medida Protetiva são estratégias de resistência que corroboram o ideal de luta por uma vida segura, algo que se constitui um direito humano de todas as mulheres.

\section{Referências}

BRASIL. 10 anos da adoção da Convenção Interamericana para Prevenir, Punir e Erradicar a Violência contra a Mulher - Convenção de Belém do Pará. Brasília: Agende, jun./2004.

Código Penal Brasileiro. Disponível em: http://www.planalto.gov.br/ccivil_03/decretolei/Del2848compilado.htm. Acesso em 27 dez. 2016.

Lei 11.340, de 7 de agosto de 2006. Cria mecanismos para coibir a violência doméstica e familiar contra a mulher, nos termos do $\S 8^{\circ}$ do art. 226 a Constituição Federal, da Convenção sobre a Eliminação de Todas as Formas de Discriminação Contra as Mulheres. Disponível em: <http://www.planalto.gov.br/ccivil_03/_ato2004-2006/2006/lei/l11340.htm>. Acesso em: 27 set. 2017.

CAVAlCANTI, S.V.S. de F. Violência Doméstica Contra a Mulher no Brasil: análise da Lei "Maria da Penha", No 11.340/06. JusPODIVM, 2012.

CUNHA, T.R.A. O Preço do Silêncio: mulheres ricas também sofrem violência. Vitória da Conquista, Edições Uesb, 2007.

DIAS, M.B. A Lei Maria da Penha na Justiça: a efetividade da Lei 11.340/2006 de combate à violência doméstica e familiar contra a mulher. $3^{a}$ ed. ver. atual. e ampl. - São Paulo: Editora Revista dos Tribunais, 2012. 

PARA MULHERES EM SITUAÇÃO DE VIOLÊNCIA DOMÉSTICA

ORGAniZAÇÃo dos estados AMERICANOS (OEA). Convenção de Belém do Pará. Pará, 1994. Disponível em: <http://www.cidh.org/Basicos/Portugues/m.Belem.do.Para.htm.> Acesso em: 20 dez. 2017.

PERSEU ABRAMO. Mulheres Brasileiras e Gênero nos Espaços Público e Privado, 2010. Pesquisa de Opinião Pública. Disponível em:

<https://apublica.org/wpcontent/uploads/2013/03/www.fpa_.org_.br_sites_default_files_pesquisaintegra.pdf $\geq$ Acesso em: 27 set. 2017.

SAFFIOTI, H.I.B. Violência Doméstica ou A Lógica do Galinheiro. In: KUPSTAS, Márcia (org.). Violência em Debate. São Paulo: Moderna, 1997. p. 39-57.

SOUZA, S.R. de. Comentários à Lei de Combate à Violência Contra a Mulher. $3^{\mathrm{a}}$ ed. Curitiba: Juruá, 2009. 


\section{Notas}

i "Entre denúncias e desistências: tecendo as memórias de mulheres em casos de violência doméstica", defendida pela autora junto ao PPGMLS/UESB, em fevereiro/2015, cuja pesquisa foi orientada por Dra. Tânia Rocha Andrade Cunha.

ii De acordo com o Art. 102 do Código Penal Brasileiro - CPB, a representação criminal é um direito facultado à vítima, pois assinando uma representação criminal, a pessoa está outorgando ao Estado poderes para investigar um crime e processar alguém. Aduz a isso o fato de que a lei também faculta à vítima a possibilidade de arrepender-se de ter representado, ou seja, o direito de retratação da representação, no entanto, essa desistência só pode ocorrer até o oferecimento da denúncia, papel que é atribuído ao Ministério Público.

iii $\mathrm{O}$ Inquérito Policial é um procedimento escrito e formal. Trata-se de uma peça informativa de apuração de um fato delituoso, no qual deve constar o conjunto de provas de que se vale o Ministério Público para o oferecimento da denúncia. Para Queiroz (2000, p. 28), “o Inquérito Policial é o instrumento pelo qual o Delegado de Polícia materializa a investigação criminal, compila informações a respeito da infração penal, de suas circunstâncias e resguarda provas futuras, que serão utilizadas em juízo contra o autor do delito".

iv Utilizamos os dados relativos a solicitações de Medidas Protetivas de Urgência a partir de 2009 porque não havia livro específico de protocolo de Requerimentos de Medidas Protetivas de Urgência à Justiça nos anos anteriores.

${ }^{v}$ Esclarecemos que esse percentual de (44\%) ultrapassou os $50 \%$ ao final da pesquisa, tendo em vista que houve procedimentos em que não havia termo de Retratação, contudo, o indiciamento do agressor não foi possível, devido às situações em que a) a vítima não mais retornou à delegacia depois do registro do Boletim de Ocorrência; b) a vítima não mais foi localizada para esclarecimentos em relação; c) óbito do agressor antes do término das investigações, dentre outros fatores.

vi A DEAM de Vitória da Conquista não funciona em regime de plantão. Desse modo, as situações que ocorrerem após as $18 \mathrm{~h} 00$, finais de semana e feriados, são atendidas pelo Plantão de Polícia que, posteriormente, encaminha os procedimentos para registro nas Delegacias Especializadas e encaminhamento à Justiça.

\section{Sobre as autoras}

Rita de Cássia Barbosa de Sousa. Mestra em Memória: Linguagem e Sociedade pelo Programa de Pós-graduação em Memória: Linguagem e Sociedade, da Universidade Estadual do Sudoeste da Bahia - PPGMLS/UESB; Doutoranda no mesmo PPG; Membro do Conselho Municipal dos Direitos da Mulher de Vitória da Conquista-BA; Escrivã de Polícia Civil do Estado da Bahia, lotada na DEAM, e Professora da Rede Estadual de Ensino. Endereço eletrônico: rcbsousa@gmail.com

Tânia Rocha Andrade Cunha. Doutora em Ciências Sociais pela Pontifícia Universidade Católica de São Paulo (2004), possui Bacharelado em Ciências Sociais pela Universidade Federal da Bahia (1980) e mestrado em Ciências Sociais pela Pontifícia Universidade Católica de São Paulo (1999). É Professora do Programa de Pós-Graduação em Memória: Linguagem e Sociedade, da Universidade Estadual do Sudoeste da Bahia/ UESB. Tem experiência na área de Sociologia, com ênfase em Sociologia, atuando principalmente nos seguintes temas: 

PARA MULHERES EM SITUAÇÃO DE VIOLÊNCIA DOMÉSTICA

violência, mulher, esfera conjugal, gênero. Endereço Eletrônico: rochandrade@uol.com.br. 